\title{
A Study on the Subjectivity about the Type of Nurses that Nursing Students Want to Become
}

\author{
Sunyoung Jang ${ }^{1}$ and MeeSuk Wang ${ }^{2}$ \\ ${ }^{1,2}$ Dept. of Nursing, Hanseo University, 46 Hanseol Ro, Haemi-myun, Seosan-si, \\ Chungcheongnam-do, 369-709, Korea \\ ${ }^{1}$ sjang@hanseo.ac.kr, ${ }^{2}$ Corresponding Author: mswang@hanseo.ac.kr
}

\begin{abstract}
This study aims to find out the subjectivity about the type of nurses that nurses and nursing students want to become, and understand the classification of nurses, using $Q$ methodology. Targeting 51 senior year nursing students, this study made them categorize 70 statements about the types of nurses. The collected data was analyzed using QUANL PC Program. The types of nurses that were recognized by nursing students were 'time-observing open type', 'time-observing responsible type', 'realistic organizational type'.
\end{abstract}

Keywords: Nurse, Nursing student, Subjectivity, Types, Classification

\section{Introduction}

\subsection{Necessity of study}

Nurses are not only having an influence on the quality of medical service and satisfaction that patients and their caretakers experience but also directly on the improvement of organizational productivity and image. it is very important for hospitals to secure and maintain sufficient number of nurses with professional nursing knowledge and techniques [1].

What is the most important for nurses to perform their professional roles is to form a therapeutic relationship between nurses and patients and the key to this is nurses understanding themselves since the ones who offer treatments are themselves. Also, as nurses have to play a professional role of satisfying patients' need by creating therapeutic or cooperative relationship with caretakers or other medical professionals [2].

Nurse practitioners are medical personnel who observe patients' changing conditions at the closest place to patients. In providing nursing care and forming rapport with patients, various communication skills are required and as nurses have to perform their tasks in organically cooperative relationship with various medical personnel with different jobs [3].

So this study uses Q-methodology and will be able to understand the types of recognition considering nursing students' subjective and individual characteristics about new nurses they are likely to become and it will be used in educating new nurses in clinical setting. Also, it will serve as basic data in coming up with ways to motivate nursing students to become nurses with qualifications [4].

\subsection{Purpose of study}

Article history:

Received (August 03, 2016), Review Result (September 09, 2016), Accepted (October 14, 2016) 
This study aims to clarify the subjective types of nurses that nursing students hope to become and characteristics of each type by applying Q-methodology. Detailed purposes of the study for this are as follows.

1) This study classifies the subjective recognition about the types of nurses that nursing students want to become.

2) Concerning the subjective recognition about the types of nurses that nursing students want to become, this study analyze, describe, and explain the characteristics of each type.

\section{Method of study}

\subsection{Planning of study}

To meet the purpose of the study, literature, media data, and previous studies on nurses were reviewed and types of subjective recognition of nurses that nursing students hope to become were examined targeting nursing students with clinical experience. The method that was conceived by Stephenson is to objectively measure attitude and subjectivity of individuals about certain objects. This method was applied to types of nurses that nursing students hope to become [5].

\subsection{Procedure of study}

\subsubsection{Selecting $Q$ population and $Q$ sample}

For Q population, in order to gain comprehensive statements about the nurse that one wants to become after graduation this study targeted nurses who are working in clinical setting and nursing students, and deduced statements by reviewing relevant literature in and out of Korea and using open-ended questionnaires and individual in-depth interviews. Data was collected through open-ended questionnaires, a total of $70 \mathrm{Q}$ sample with high discrimination were selected [6].

\subsection{Sampling method}

\subsubsection{P sample}

Q-methodology is a qualitative research that focuses on differences of significance and importance inside individuals and emphasizes the subjectivity of individual, not on the differences between individuals. $\mathrm{P}$ sample of this study is nursing students of $\mathrm{H}$ University and 51 of those who agreed to participate in this study were selected [7].

\subsection{2. $Q$ classification}

Q sample classification is a process of forced distribution of Q samples on Q sample distribution table and this study used the principle of Q methodology so the distribution is close to normal distribution. After reading the 70 prepared samples, participants were made to do forced distribution by choosing a card with a statement that is the closest to one's view, 1 card of 'very positive'(+7), 8 cards of 'neutral'( 0$)$, and 1 card of 'very negative'(-7).

\subsection{Q Classification process and method}


Q classification process is a process that participants who are chosen as P samples classify the statements of Q samples using forced normal distribution method and it is a process of making definition of nurse that one wants to become. First of all, days when data could be collected were assigned. Then, time was adjusted so that nursing students chosen as P samples could give answers and data was collected. The place of data collection was selected to be the place that the participants wanted such as a meeting room where it is quiet and the privacy of the participant can be protected. The time was set not to affect the participants' work or study. Targeting 51 nursing students.

\subsection{Data analysis}

The analysis of data was carried out using QUNAL pc program and Q factor analysis was conducted through principal component factor analysis. The average and standard deviation of factors were analyzed using SPSSWIN 21.0.

\subsection{Ethical considerations}

Prior to the study, voluntary agreement from all participants was attained and it was explained to them and their legal representatives that they were at liberty to withdraw from the study at any time. In order to respect the rights of the subjects and ensure the confidentiality of their private and personal information, all data collected for this study were processed anonymously, coded and underwent Q-sorting during the data analysis process.

\section{Result of study}

\subsection{Characteristics of types of nurses that nursing students want to become}

\subsubsection{Structure of $Q$ type}

As a result of $\mathrm{Q}$ factor analysis of the subjectivity of expressing the types of nurses that nursing students want to become using QUNAL pc program, 3 factors were deduced.

\subsubsection{Characteristics of types of nurses that nursing students want to become}

Analyzing the subjectivity of nurses using PC QUANL program, there were 3 factors, which explained $25.96 \%$ of the total variables. Factor 1 took $13.95 \%$, factor 2, 6.67\%, and factor $3,5.34 \%$. As factor 1 took $13.95 \%$ of explanation power, it can be seen as the most common image of nurses.

\subsubsection{Analysis of each type}

The following is the types of subjectivity about the types of nurses that nursing students want to become deduced by the above mentioned factor analysis method.

- Time-Observing Open Type: Those who belong to factor 1 are made up of 23 people [Table 1]. Among them, the one with the highest factor weight is participant No. 45 (1.010). The statements that were most agreed upon among type 1 were No. 1, 'Nurses who get to work on time' $(Z=1.96)$, which was followed by No. 9, 'Nurses who do their best and fulfill their responsibility' $(Z=1.89)$, No. 69 , 'Nurses who care about patients with sincerity and give courage', No. 66, 'Nurses with personal emotional supporting system'. Based on these statements, these types of nurses were recognized as 'time-observing opening type'. 
Table 1. Q-statements on new nurse images type of representative items and Z-scores $(\mathrm{N}=51)$

\begin{tabular}{|c|c|c|c|c|}
\hline Factor & No & Description & Mean (SD) & Z-score \\
\hline \multirow{3}{*}{$\begin{array}{l}\text { Factor } 1 \\
(\mathrm{~N}=23)\end{array}$} & 1 & Nurses who get to work on time & $10.65(3.880)$ & 1.96 \\
\hline & 9 & $\begin{array}{l}\text { Nurses who do their best and fulfill their responsi- } \\
\text { bility }\end{array}$ & $11.09(2.762)$ & 1.89 \\
\hline & 69 & $\begin{array}{l}\text { Nurses who care about patients with sincerity and } \\
\text { give courage }\end{array}$ & $10.65(3.142)$ & 1.87 \\
\hline \multirow{3}{*}{$\begin{array}{l}\text { Factor } 2 \\
(\mathrm{~N}=13)\end{array}$} & 5 & Diligent nurses who are not late or absent & $\begin{array}{l}12.15 \\
(2.853)\end{array}$ & 2.64 \\
\hline & 1 & Nurses who get to work on time & $\begin{array}{c}12.15 \\
(3.262) \\
\end{array}$ & 2.54 \\
\hline & 9 & $\begin{array}{l}\text { Nurses who do their best and fulfill their responsi- } \\
\text { bility }\end{array}$ & $\begin{array}{c}10.77 \\
(3.059)\end{array}$ & 1.78 \\
\hline \multirow{3}{*}{$\begin{array}{l}\text { Factor } 3 \\
(\mathrm{~N}=15)\end{array}$} & 5 & Diligent nurses who are not late or absent & $\begin{array}{c}11.20 \\
(3.668)\end{array}$ & 2.28 \\
\hline & 32 & $\begin{array}{l}\text { Nurses who understand the direction of work and } \\
\text { predict proper questions and results }\end{array}$ & $\begin{array}{c}11.13 \\
(1.885) \\
\end{array}$ & 1.95 \\
\hline & 23 & Nurses who are ready to learn new work & $\begin{array}{c}10.13 \\
(3.270)\end{array}$ & 1.90 \\
\hline
\end{tabular}

- Time-Observing Responsible Type: A total of 13 people were categorized as factor 2 [Table1]. Participant No. 36 showed the lowest factor weight $(0.216)$ in factor 2 . The statement that participants showed the strongest positivity in type 3 was No. 5, 'Diligent nurses who are not late or absent' ( $\mathrm{Z}=2.64)$, which was followed by No. 1, 'Nurses who get to work on time $(Z=2.54)$, No. 9, 'Nurses who do their best and fulfill their responsibility' $(Z=1.78)$, No. 23 , 'Nurses who are ready to learn new work' $(Z=1.74)$. Based on these, type three was recognized as 'time-observing responsible type', the people who accomplish their work for themselves with responsibility.

- Realistic Ideal Type: In factor 3, the participant with the lowest factor weight was No. $9(.255)$. The statement that the participant of factor 3 showed the strongest negativity was No. 42 , 'Nurses who do not perceive developmental innovations and changes as problems' $(Z=-$ 4.23), which was followed by No. 18, 'Nurses who acquire their seniors' experience and keep growing up' ( $Z=-2.04)$, No. 52, 'Nurses who make efforts for improving relationship with the members of their department' ( $Z=-1.65)$, No. 59, 'Nurses who understand emotional richness and have composure in life' $(Z=-1.60)$. These nurses were recognized as a type who value consolidation with members of their department and learn about tasks from seniors, those who are punctual and handle their work in a leisurely manner.

\section{Discussion}

This study started with the intention of providing basic data for developing job education programs for nursing students using subjective data that found out the types of nurses that nursing students want to become and analyzed the types.

Type 1 that was found in this study was time-observing open type. In factor 1 , the participant with the highest factor weight was participant No. $45(\mathrm{Z}=2.76)$. This participant thought nurses who put patients before anything else are important. The statements that was most agreed upon among type 1 was No. 56, 'Nurses who recognize patients as human beings not as disorders or damages' $(Z=1.70)$. The statement that participants showed the strongest positivity in type 1 was 'Nurses who represent patients and caretakers and help their 
communication with medical professionals' $(\mathrm{Z}=1.56)$ and 'Nurses who care about patients with sincerity and give courage'.

Type 2 is time-observing responsible type. Participant No. 45, who marked factor weight of 4.843 in factor 2 said that for nurses punctuality takes priority and the effort to get used to one's work is the most important. Participants said it is important to learn how to deal one's tasks to fulfill one's work. The statements that showed strong positivity in factor 2 were 'nurses who express and deliver their ideas concisely and clearly', 'nurses who read the other's emotional status and lead conversation with a considerate mind', and 'nurses who are ready to learn new work'.

Type 3 is realistic organizational type. Participant No. 27 with the highest factor weight of 1.0314 in factor 3 thought that it takes priority to be puncture and to go to work early and check medical equipment and goods. He/she said it is the most important as the image of new nurses to go to work early and get prepared. The statements that participants showed the strongest positivity in factor 3 were 'diligent nurses who are not late or absent', 'nurses who go to work on time', and 'nurses who learn their tasks with patience'.

As for the type of nurses that nurses wanted to work together, they preferred timeobserving responsible type the most, and experienced nurses perceived warm sympathizing type, prudent learner type, considerate and working as a calling type as what are needed after completing one's work [8].

\section{Conclusion}

This study tried to find out the type of nurses that nursing students want to become, analyze their features, and aimed at coming up with base data for the development of education and training of nursing students in education and employment programs.

Type 1 was named time-observing open type. Type 2 was named time-observing responsible type. Type 5 was named realistic organizational type. Type 3 was named realistic ideal type, those who pursue the integrated ability about organization, department, and hospital environment while learning and conducting tasks. By understanding the types of nurses that nursing students want to become, it is possible to develop employment and education programs for nursing students.

\section{References}

[1] Y. J. Kim, H. K. Song, and M. A. Lee, "J. Perceived relationship among professional self-concept, head nurse's leadership, and nursing clinical competency by clinical nurses," Journal of Korean Academy of Nursing, vol.17, no.1, pp.96-105, (2011)

[2] H. S. Oh and H. S. Kim. J, "A comparative study on enneagram personality type and developmental level of nursing students of college,” J. Enneagram Stud, vol.3, no.2, pp.63-91, (2006)

[3] K. S. Han, E. Peak, Y. H. Park, H. S. Lim, E. M. Lee, L. Kim, D. Ahn, and H. Kang. J, "Factors influencing sleep quality in clinical nurses," J. Korean Acad, Psychiatr Ment, Health Nurse, vol.20, no.2, pp.121-131, (2011)

[4] H. G. Kim, "Q methodology : philosophy, theories, analysis, and application," Communication Books, Seoul, (2008)

[5] S. Brown, "Political Subjectivity: Application of Q Methology," New Heaven:Yale University, Press, (1980)

[6] N. Akhtar-Danesh, A. Baumann, and L. Cordingley, "Q methodology in nursing research: A promising method for the study of subjectivity," Western Journal of Nursing Research, vol.30, no.6, pp.759-773, (2008) DOI:10.1177/0193945907312979 
[7] S. M. Whang, S. W. You, J. Y. Kim, and R. G. Kim, "Consumer types and cultural consumption characteristics of korean society: Who spends for what reasons?” Journal of Human Subjectivity, no.13, pp.25-39, (2006)

[8] S. Y. Jang and M. S. Wang, "A study on newly licensed nurse types that nurses in comprehensive nursing service hospitals want to have as part of their team," Science \& Engineering Research Support Society, vol.8, no.1, pp.133-142, (2016)

\section{Authors}

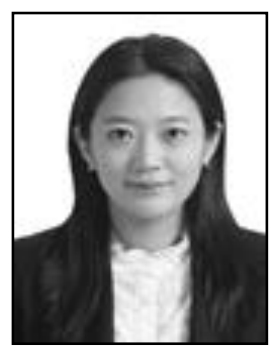

\section{Sunyoung Jang}

She is an assistant professor in Hanseo University, Seosan-si, South Korea. Her research areas include healthcare technology assessment, systematic review, meta-analysis, nurse-staffing and nursing management.

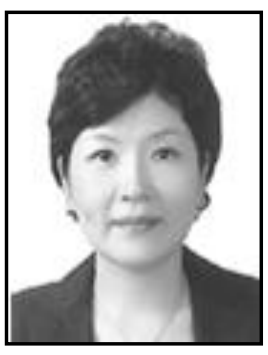

\section{Meesuk Wang}

She is an assistant professor in Hanseo University, Seosan-si, South Korea. Her research areas include Women`s healthcare, Aged care, Clinical nurse. 